\title{
A trajetória da introdução e regulamentação da acupuntura no Brasil: memórias de desafios e lutas
}

\author{
The trajectory of the introduction and regulation of acupuncture \\ in Brazil: recollections of the challenges and struggles
}

Sabrina Pereira Rocha ${ }^{1}$

Maria Auxiliadora Craice De Benedetto ${ }^{1}$

Fabíola Holanda Barbosa Fernandez ${ }^{2}$

Dante Marcello Claramonte Gallian ${ }^{1}$
${ }^{1}$ Escola Paulista de Medicina, Universidade Federal de São Paulo. R. Botucatu 720 , Vila Clementino. 04023-062 São Paulo SP Brasil. sp.rocha1986@uol.com.br ${ }^{2}$ Departamento de História, Núcleo de Ciência da Educação, Universidade Federal de Rondônia.

\begin{abstract}
Based on the life experiences of acupuncturists, the scope of this study was to examine the struggle to obtain regulation of the practice of acupuncture in Brazil. The method used was Oral Live History, the core issue being the dimension of the human experience involved in this trajectory of struggles and challenges. We conducted ten interviews, following the set of procedures demanded by the Oral History technique. The information contained in the narratives was analyzed and, taking the interpretive approach called immersion/crystallization as a benchmark, the central themes of the work were established, based on which which the discussion was developed. The results indicate the emergence of highly controversial themes involving political, corporate and cultural aspects, which constitute central elements within a historical process still under development.
\end{abstract}

Key words Acupuncture, Oral history, Interview, Regulations by policy organizations
Resumo O presente estudo objetivou explorar, a partir de relatos de vida de acupunturistas, a luta pela regulamentação da prática da acupuntura no Brasil. Utilizamos a História Oral de Vida como método, tendo como proposta central a dimensão das experiências humanas envolvidas nesta trajetória de lutas e desafios. Realizamos dez entrevistas, seguindo o conjunto de procedimentos exigidos pela História Oral. As informações contidas nas narrativas foram analisadas e, tomando como referencial a abordagem de interpretação denominada imersão/cristalização, foram estabelecidos os temas centrais do trabalho, a partir dos quais a discussão foi desenvolvida. Os resultados apontaram a emergência de temas extremamente controversos que envolvem aspectos politicos, corporativos e de âmbito cultural, que se apresentam como elementos centrais dentro de um processo histórico ainda em desenvolvimento.

Palavras-chave Acupuntura, História oral, Entrevista, Regulamentação de organismos de política 


\section{Introdução}

Desde a década de 1970, a Organização Mundial de Saúde vem incentivando o uso da acupuntura e de outras práticas alternativas pelos países membros. Posteriormente, criou-se um documento intitulado "Estratégia da OMS sobre Medicina Tradicional (MT) 2002-2005”, com o objetivo de promover o desenvolvimento de políticas para a implantação de Medicina Tradicional e estabelecer requisitos de segurança, eficácia, qualidade, uso racional e acesso ${ }^{1}$.

Originada de um conjunto de conhecimentos teórico-empíricos da Medicina Tradicional Chinesa (MTC), a acupuntura é uma tecnologia de intervenção em saúde que aborda de modo integral e dinâmico o processo saúde-doença no ser humano, podendo ser usada isoladamente ou de forma integrada com outros recursos terapêuti$\cos ^{2,3}$.

A MTC é constituída por um vasto campo de saberes e práticas, o qual, embora aparente ao leigo um alto grau de homogeneidade, revela a um olhar minucioso considerável heterogeneidade. Em seu aspecto positivo, a diversidade enriquece o campo, mas no negativo é fonte de tensões e conflitos que definem algumas fronteiras internas ${ }^{4}$.

O diagnóstico na MTC, assim como em qualquer sistema médico, é um pré-requisito para a determinação do tratamento e visa compreender como o paciente se insere dentro do seu contexto de vida e de que maneira interage com os fatores que o cercam. Esta abordagem é a aplicação prática da filosofia chinesa que vê o ser humano (microcosmo) em constante interação com o mundo (macrocosmo). O padrão de resposta de cada indivíduo, em dado momento, é categorizado em síndromes. A partir desse diagnóstico, é definido o plano de tratamento ${ }^{3,5}$.

Muitos países vêm realizando a regulamentação da prática da acupuntura e o perfil de profissional exigido para tal varia de país para país, sendo que, em parte deles é necessária a formação em medicina ocidental como principal requisito. No Brasil, a acupuntura é considerada uma especialidade médica pelo Conselho Federal de Medicina, o qual defende a exclusividade de sua prática por médicos. Entretanto, conselhos de outras categorias profissionais de saúde também reconheceram a acupuntura como especialidade. Desta maneira, esta tem sido exercida por uma gama variada de profissionais que inclui acupunturistas com formação no exterior, práticos com formação em cursos livres no Brasil, técnicos em acupuntura e especialistas em acupuntura. Este cenário acabou gerando dilemas ético-legais quanto o direito ao exercício dessa terapêutica no país ${ }^{1}$.

No Brasil, a prática da MTC se iniciou com a vinda dos primeiros imigrantes chineses para o Rio de Janeiro, em 1810. Em 1908, os imigrantes japoneses inseriram a acupuntura japonesa, embora restrita à colônia. Em 1958, Friedrich Spaeth, fisioterapeuta, considerado responsável pela difusão da acupuntura na sociedade brasileira na década de 1950, começou a ensinar esta prática milenar no Rio de Janeiro e em São Paulo e, em 1972, foi fundada a Associação Brasileira de Acupuntura $(\mathrm{ABA})^{6}$.

A tentativa de estabelecimento da acupuntura no Brasil foi marcada principalmente pelo repúdio da classe médica; em decorrência disto, a introdução e o desenvolvimento inicial desta prática milenar foram realizados por profissionais de outras áreas. Nesta perspectiva, a acupuntura passou por um período caracterizado pela marginalização antes que ocorresse sua efetiva aceitação pela classe médica.

Os conflitos decorrentes do processo de importação' e aculturação de um sistema médico exógeno nos países ocidentais resultaram em distintas configurações institucionais, conforme os poderes dos atores e das instituições envolvidas, tais como as associações e os conselhos profissionais; as características das leis trabalhistas e educacionais; o sistema nacional de saúde; a história prévia da imigração de orientais; e as instituições de pesquisa, construção e legitimação do conhecimento, entre outros ${ }^{4}$.

Na década de 1980, tanto os movimentos organizados da sociedade civil, seja em associações comunitárias seja posteriormente em ONGs, como a demanda social da clientela para serviços públicos de saúde crescentemente pressionaram as instituições médicas no sentido de uma "abertura" para as medicinas ditas alternativas?.

Um marco importante nesta década foi a Declaração de Veneza, em 1986, que voltou os olhares para a existência de outras fontes e formas de saber. A declaração desencadeou intensos debates ao sugerir um diálogo entre a ciência e outras formas de conhecimento. A partir de então a ciência e a tradição passaram a ser vistas não como contraditórias, mas complementares ${ }^{8}$.

$\mathrm{Na}$ década de 1980, os Conselhos de Classe iniciaram reconhecimento da acupuntura através da criação de uma série de resoluções:

[...] Conselho Federal de Fisioterapia e Terapia Ocupacional (Resolução COFFITO-60, 1985); Conselho Federal de Biomedicina (Resolução no 02, 1986); Federação Nacional de Profissionais de Acu- 
puntura, Moxabustão, Do-In e Quiroprática (registro no Ministério do Trabalho no 24000.000345, 1991); Conselho Federal de Medicina (Resolução CFM 1455/95, 1995); Conselho Federal de Enfermagem (Parecer CTA no 004, 1995); Conselho Federal de Farmácia (Resolução CFF no 353/00, 2000); Conselho Federal de Fonoaudiologia (Resolução CFFa no 272, 2001) e o Conselho Federal de Psicologia (CFP 005, 2002) $)^{9}$.

Embora, a partir da década de 1980, o sistema público brasileiro de assistência à saúde tenha absorvido profissionais acupunturistas em alguns hospitais e postos de saúde nos grandes centros, o processo de expansão da acupuntura nas demais instituições públicas vem sendo dificultado pela polêmica entre médicos e não médicos ${ }^{9}$.

Assim, a história desse processo de institucionalização vem se inscrevendo com muitos percalços no Brasil, especialmente na última década, tendo seu percurso encontrado obstáculos constantes interpostos pela medicina socialmente hegemônica. Nesta obstaculização, o saber médico científico funciona como elemento às vezes de censura, às vezes de comprovação ${ }^{7}$.

Em nosso país, a prática da Acupuntura foi introduzida na tabela do Sistema de Informação Ambulatorial - SIA/SUS em 1999, através da Portaria no $1230 / \mathrm{GM}^{2}$, e sua prática reforçada pela Portaria 971, publicada pelo Ministério da Saúde em 2006, que aprovou a Política Nacional de Práticas Integrativas e Complementares no Sistema Único de Saúde (SUS). Este documento define que no SUS, sejam integrados abordagens e recursos que busquem estimular os mecanismos naturais de prevenção de agravos e de recuperação da saúde, sobretudo, os com ênfase na escuta acolhedora, no desenvolvimento do vínculo terapêutico e na integração do ser humano com o meio ambiente e com a sociedade ${ }^{2}$.

Existe um grande número de profissionais acupunturistas no Brasil, mas há também uma forte disputa política e jurídica pelo direito de exercer a prática da acupuntura9 ${ }^{9}$.

$O$ presente artigo mostra os resultados de um projeto de pesquisa cujo objetivo foi verificar os problemas e desafios concernentes à inserção e regulamentação da acupuntura no Brasil de acordo com a visão dos profissionais acupunturistas que se destacaram em tal processo. Para tal, buscou-se compreender seus discursos, suas experiências de vida e as "intempéries" por eles atravessadas na busca da introdução e do reconhecimento desta prática, seja lutando por sua democratização, ou seja, defendendo sua restrição aos médicos.
Este estudo foi aprovado pelo Comitê de Ética em Pesquisa da Universidade Federal de São Paulo (UNIFESP) e todos os participantes concordaram e assinaram o Termo de Consentimento Livre e Esclarecido, tendo declinado da manutenção do anonimato.

\section{Metodologia}

Em decorrência da procura por uma compreensão mais ampla do significado individual e coletivo para as questões a serem estudadas, optamos por métodos qualitativos fundamentados na abordagem da História Oral de Vida, uma vez que esta não tem o propósito singular de entender o que ocorreu na história, "mas sim a intenção de se ver como o que aconteceu no passado e o que acontece no presente está sendo interpretado e ressignificado na memória [...]"10. Por ser um instrumento capaz de revelar as diferentes maneiras de perceber, sentir e atuar dos acupunturistas na sua realidade cotidiana ${ }^{11}$ e também por ser uma abordagem que permite abarcar a perspectiva das vivências subjetivas de maneira mais ampla que as entrevistas em profundidade, a História Oral de Vida adequou-se plenamente ao nosso estudo.

Convém lembrar que, nesta pesquisa, a História Oral não foi pensada como uma técnica auxiliar da História, no sentido tradicional, visto que não se caracteriza como um mero instrumento para a produção de documentos históricos. A História Oral também "gera, sem dúvida, documentos, registros, mas estes, mais do que documentos da História, devem ser vistos como documentos ou registros da memória"10.

Para garantir a ética e a validade dos documentos originados, a História Oral de Vida segue um rigoroso conjunto de procedimentos para a constituição das narrativas ${ }^{11}$, procedimentos esses que podem ser colocados nas seguintes etapas: (1 $\left.{ }^{a}\right)$ gravação das entrevistas; (2a) confecção do documento escrito: transcrição, textualização, transcriação; ( $3^{a}$ ) conferência e validação do documento escrito; (4a) análise; (5a) devolução do produto.

Os colaboradores desta pesquisa, termo que se prefere utilizar em História Oral no lugar de participantes, foram selecionados por serem profissionais acupunturistas - médicos e não médicos - que participaram ou estiveram envolvidos, de alguma forma, na inserção e/ou regulamentação da acupuntura em nosso país. Partimos de um "ponto zero", ou seja, de um primeiro 
colaborador escolhido para ser entrevistado, por representar personagem marcante no processo de inserção/regulamentação da acupuntura no Brasil e conhecer a história do grupo de pessoas-chave envolvidas neste processo. A partir de sua entrevista foi-se constituindo uma rede de colaboradores $^{12}$, cujas características gerais são mostradas no Quadro 1, em que os colaboradores estão enumerados de acordo com a ordem de inclusão ao projeto.

Convém ressaltar que, na abordagem da História Oral de Vida, não são as perguntas e as questões do entrevistador/pesquisador que norteiam e determinam o fluxo e a construção da narrativa do entrevistado, mas é a dinâmica própria da memória deste que a norteia, produzindo assim um documento muito mais rico do ponto de vista fenomenológico. Isso não quer dizer que, na abordagem da História Oral de Vida, não possa o entrevistador formular perguntas, porém estas surgem mais como um recurso de esclare- cimento e de explicitação de acompanhamento do ouvinte em relação ao narrador, responsável principal e condutor do fluxo narrativo. Neste sentido, a entrevista de História Oral de Vida pode ser considerada como uma entrevista aberta não diretiva, conforme definido por sociólogos e antropólogos que se utilizam deste recurso em pesquisa qualitativa ${ }^{12}$.

Cumpridas as três primeiras etapas exigidas pela mencionada metodologia, foram gerados textos em primeira pessoa correspondentes às narrativas de cada um dos colaboradores, resultantes da passagem do registro sonoro da entrevista num relato literário, fiel ao mesmo tempo à fala do narrador e aos cânones fundamentais do código escrito. Estes textos foram interpretados de acordo com técnicas de imersão/cristalização, estilo de interpretação fundamentado na Fenomenologia Hermenêutica ${ }^{13}$. De tal forma, emergiram subtemas, os quais foram reunidos em dois grandes temas, os quais são apresentados em

Quadro 1. Características gerais dos colaboradores.

\begin{tabular}{|c|c|c|c|}
\hline Colaboradores & Formação & Instituição/Cargo & $\begin{array}{c}\text { Aproximação/Acupuntura } \\
\text { (Década) }\end{array}$ \\
\hline Dr. Ysao Yamamura & Medicina & $\begin{array}{c}\text { UNIFESP } \\
\text { Chefe do Dep. Acupuntura }\end{array}$ & 1970 \\
\hline $\begin{array}{l}\text { Dra. Célia Regina Whitaker } \\
\text { Carneiro }\end{array}$ & Medicina & $\begin{array}{c}\text { UNIFESP } \\
\text { Docente e Pesquisadora }\end{array}$ & 1990 \\
\hline Dr. Renato Massaki Ito & Medicina & $\begin{array}{c}\text { UNIFESP } \\
\text { Preceptor de Acupuntura }\end{array}$ & 2000 \\
\hline Dr. Wu Tou Kwang & Medicina & $\begin{array}{c}\text { CEATA } \\
\text { Fundador, Presidente e Docente }\end{array}$ & 1970 \\
\hline Dr. Francisco Moreno Carvalho & Medicina & $\begin{array}{l}\text { NASF/Tucuruvi } \\
\text { Médico de Família }\end{array}$ & 1980 \\
\hline Dr. Evaldo Martins Leite & Medicina & $\begin{array}{c}\text { ABA } \\
\text { Presidente }\end{array}$ & 1950 \\
\hline Dr. Delvo Ferraz da Silva & Psicologia & $\begin{array}{l}\text { SOBRAPA } \\
\text { Presidente }\end{array}$ & 1980 \\
\hline Dr. Geraldo Adélio de Borba & $\begin{array}{l}\text { Técnico } \\
\text { Fisioterapia }\end{array}$ & $\begin{array}{c}\text { EOMA } \\
\text { Docente } \\
\text { Atendimento particular }\end{array}$ & 1980 \\
\hline Akemi Nagao & Técnico & Atendimento Particular & 2000 \\
\hline Tadamichi Yamada & Técnico & $\begin{array}{c}\text { EOMA } \\
\text { Fundador e Presidente }\end{array}$ & 1960 \\
\hline
\end{tabular}




\section{Resultados e discussão}

\section{Inserção, rupturas e ato médico}

Na década de 1970, a acupuntura ainda sofria uma importante resistência por parte dos conselhos de medicina, que a classificavam como "charlatanismo" e "crendice", conforme foi apontado por alguns colaboradores. A conjuntura autoritária que marcou esta época colaborou para que a intolerância médica à acupuntura viesse a se traduzir em atos que ameaçaram e por vezes atingiram com prisão e processos criminais alguns acupuntores, particularmente aqueles que não possuíam formação em medicina ocidental ${ }^{14}$.

Os profissionais médicos e não médicos, mesmo antes da década de 1970, como é o caso de um de nossos entrevistados, Dr. Evaldo Martins Leite, atualmente presidente da ABA, já demonstravam o interesse e procuravam uma forma de aprender mais sobre a acupuntura. Segundo o relato do Dr. Geraldo, apesar de não comentarem, muitos dos "médicos acupunturistas conhecidos aqui em São Paulo, como o Wu, o Rui e o Ysao, tiveram formação na ABA com o Doutor Evaldo e um quadro de professores não médicos".

De acordo com Marilene Cabral do Nascimento $^{14}$, a polêmica relacionada à definição profissional para a prática da acupuntura formou facções no interior da corporação, o que desencadeou uma divisão da Associação Brasileira de Acupuntura (ABA). Em 1984, foi fundada a Sociedade Médica Brasileira de Acupuntura (SMBA), reunindo um grupo de médicos acupuntores descontentes com a postura defendida na $\mathrm{ABA}$ de regulamentação da profissão não restrita a médicos.

Segundo o Dr. Francisco Moreno, na década de 1980 começou um movimento de organização da acupuntura dentro dos trabalhos dos médicos e isso desencadeou a formação da Associação Médica Paulista de Acupuntura, que defendia a prática da acupuntura restrita a médicos.

O Dr. Geraldo acrescenta que: "desde a década de 1980 já havia rumores sobre a restrição

da acupuntura à classe médica e, no entanto, até hoje ela não está devidamente regulamentada".

Posteriormente, como colocado pelo Dr. Francisco, com o surgimento de cursos no Estado de São Paulo e em outros estados, formou-se um agrupamento de profissionais com a mesma concepção, de que a acupuntura deveria ser uma prática exclusiva aos médicos, o que culminou na criação da Associação Médica Brasileira de Acupuntura. Nesta época, não havia o reconhecimento da acupuntura como especialidade médi$\mathrm{ca}$, mas havia essa luta para conseguir este status para a citada prática, visto que já havia algumas tentativas de introdução da acupuntura no serviço público.

Dr. Francisco explica ainda que um risco muito abordado na época era a formação de "um profissional que não teria uma qualificação mínima em saúde e que não responderia pelos seus atos a nenhum conselho". Ele acredita que essa questão da regulamentação da acupuntura no Brasil é, além de importante, fundamental e necessária.

Dr. Evaldo explica que nos primeiros eventos multiprofissionais organizados pela Associação Brasileira de Acupuntura havia uma grande presença de médicos, porém:

[...] começou haver certa conviç̧ão por parte de alguns médicos que somente eles poderiam fazer acupuntura e não concordamos. Quem deve fazer acupuntura é quem sabe, sendo médico ou não... [...] Então, infelizmente, houve essa separação e hoje temos, portanto, uma dicotomia muito evidente, médicos e não médicos lutando em campos diferentes...

Como mencionado, o Conselho Federal de Medicina era contra a prática da acupuntura e, como coloca Dr. Delvo Ferraz da Silva, "dizia que não tinha correlação com a medicina”. Segundo ele:

Quando alguns conselhos começaram a regulamentar, por exemplo, a Biomedicina e a Fisioterapia, a Medicina regulamentou também como sendo uma prática médica. Neste momento, algumas lideranças começaram a reivindicar e trazer como bandeira principal que a acupuntura deveria ser feita única e exclusivamente por médicos. No entanto, não são todos os médicos que pensam desta forma.

Dr. Delvo acrescenta ainda que:

Nós vivemos em um país extremamente carente. Na época [década de 1980], nós, os universitários, representávamos um por cento da população. Portanto, 99 por cento não tinha tido nenhum acesso à educação plena, entendendo como uma condição de ter acesso e conseguir terminar uma 
graduação. Então o que se discutia e discute até hoje é algo muito pequeno. Estamos numa discussão corporativista; esse corporativismo ao qual me refiro, infelizmente, é selvagem e canibal, que acredita que só se vai existir se o outro for destruído...

Desta forma, foi possível perceber que a ruptura entre a categoria médica e as demais foi marcada por intenso debate.

O problema inicial da discussão sobre a exclusividade da prática de acupuntura para os médicos está relacionado inicialmente à inexistência de uma regulamentação da medicina, o que nos remete à questão do ato médico.

A regulamentação da acupuntura depende do Ato Médico. A medicina é a única atividade profissional que não apresenta uma regulamentação das suas competências, talvez pelo fato de ser a mais antiga profissão. No momento em que o Ato Médico for regulamentado, a acupuntura será especialidade médica sem contestação. (Dr. Ysao)

Essas entidades [Sociedade Brasileira de Acupuntura, Associação Médica Brasileira de Acupuntura e o Colégio Médico de Acupuntura] consideram a acupuntura um ato médico, só que nem o ato médico foi regulamentado até hoje. (Dr. Wu)

Entre as categorias universitárias da área da saúde, o médico é o único que não tem a profissão regulamentada. É justo que a classe médica tenha a profissão regulamentada por lei [...]. (Dr. Delvo)

Entre os diversos argumentos formulados pela classe médica sobre o risco da multiprofissionalização da prática de acupuntura destacase a questão do diagnóstico, que se caracteriza como uma prática exclusivamente médica ${ }^{15}$, o que também pode ser revelado nas narrativas dos colaboradores. De acordo com o Conselho Federal de Medicina, a acupuntura trata doenças e, no Brasil, "diagnóstico e tratamento de doenças são atividades exclusivas de médicos"15.

O problema no caso acupuntura é que tem a parte da técnica e a parte do conhecimento. [...] para diagnosticar, além da parte clínica, precisa pedir exames, interpretar exames, que é competência médica [...] inserção de agulha é a coisa mais fácil que tem... é só inserir a agulha! Essa inserção qualquer pessoa pode estar fazendo. O problema todo é o diagnóstico. [...] Um médico que estudou seis anos, fez residência e especialização, pode ainda cometer alguns erros de diagnóstico. E quanto aos não médicos, que não têm nenhum preparo e nem conhecimento médico? Talvez o erro será bem grande... (Dr. Ysao)

A posição do Colégio Médico de Acupuntura e a minha posição pessoal é que a acupuntura é um ato médico, porque precisa saber Medicina para tratar doentes. Se um paciente apresenta um determinado sintoma, pode ser apenas um sinal de desequilíbrio, embora possa ser uma doença estabelecida, e o não médico é incapaz de saber detectar. [...] O não médico não terá um refinamento de entendimento de doenças para fazer um diagnóstico da causa do sintoma. Então, a acupuntura é um ato médico e deveria ser restrito aos médicos, é a minha opinião e, logicamente, da maior parte dos médicos. (Dra Célia)

É notável a diferença filosófica da medicina científica ocidental e a MTC, diferença esta que sobressai no quesito do diagnóstico. O diagnóstico na MTC e, portanto, na acupuntura, é mais sutil, pois envolve, além da avaliação física, uma profunda investigação do estado emocional e da vida da pessoa. Em contrapartida ao argumento das entrevistas anteriores, Dr. Delvo e o Dr. Evaldo ressaltam que:

[...] esse tipo de saber [em que diagnóstico e intervenção são montados a partir da ideia de desequilíbrio e reequilíbrio energético] é completamente estranho para nós, os ocidentais; ele não nasceu na medicina alopática, pelo contrário, é muito diferente [...]. O profissional graduado na área da saúde precisa de um treino [...]. Então não teria sentido fazer um diagnóstico alopático pensando no equilíbrio do Yin e do Yang, já que são estruturas de pensamento diferentes. O diagnóstico ocidental tem objetivos próprios e estrutura própria de pensamento, foi feito para uma realidade diferente, para uma intervenção terapêutica específica, usá-lo pensando na estrutura da medicina tradicional chinesa é incabivel. O diagnóstico alopático é importante e a ideia central é trabalhar em conjunto, de acordo com a proposta das Nações Unidas. (Dr. Delvo)

[...] a acupuntura de qualidade tem seu diagnóstico próprio; o acupunturista não precisa tanto do diagnóstico ocidental, se tiver esse diagnóstico também, ótimo. [...] Outra questão interessante é que normalmente os brasileiros que fazem acupuntura só procuram este tratamento como último recurso... já procuraram médicos, têm um monte de exames e de diagnósticos, muitas vezes conflitantes; já foram em benzedeira, não deu certo, por fim resolveram procurar acupuntura... Portanto, essa questão do diagnóstico é um argumento de quem não tem argumento. (Dr. Evaldo)

A inserção e a manipulação da agulha de acupuntura também são consideradas um risco por alguns médicos, sendo a acupuntura caracterizada como um procedimento invasivo. O Projeto do Ato Médico (PLS 268/2002) prevê como exclusivo de médicos "procedimentos invasivos, sejam diagnósticos, terapêuticos ou estéticos, incluindo 
acessos vasculares profundos, biópsias e endoscopia", o que inclui a "invasão da pele atingindo o tecido subcutâneo da pele para injeção"16.

No entanto, assim como mencionado pelo Dr. Wu, a acupuntura apresenta uma ampla variedade de outros métodos e técnicas, não estando, assim, restrita à utilização de agulhas ${ }^{17}$.

Em relação à elaboração do PSL 268/2002, segundo Dr. Delvo:

... [os médicos] acabaram extrapolando um 'pouquinho' os seus objetivos ou deixando claro demais quais eram esses objetivos. [Os médicos invadiram] outras categorias que já foram regulamentadas por lei. Apresenta um caráter estranho, invadindo a questão do ensino, da administração do serviço de saúde e do que seria privativo ou não dessa categoria, não observando ou mesmo desrespeitando as outras categorias.

Outra questão muito abordada pelos médicos acupunturistas é sobre o risco da ocorrência de pneumotórax. Segundo Jonas e Levin ${ }^{18}$, diversos casos de pneumotórax foram documentados e a maioria deles apresenta vínculo causal com acupuntura. Enquanto que para Bauer ${ }^{19}$, a maioria dos casos de pneumotórax não envolve acupuntura e explica ainda que isso pode ocorrer por diversos motivos. Sobre a ocorrência de pneumotórax, Dr. Evaldo afirma que:

Existe também o risco de pneumotórax, até hoje a maioria foi causada por médicos; na realidade grande parte dos acidentes por acupuntura foi causado por médicos... mas infelizmente não mencionam isso, assim como esquecem de dizer que a incidência de problemas decorrentes do uso de acupuntura é insignificante.

Dr. Francisco adverte que há uma grande necessidade de regulamentação das profissões de saúde e diz ainda que:

[...] a prática de acupuntura não é diferente, até mesmo por ser, bem ou mal, invasiva. Tem que ter cuidado com agulha, com uso de material de qualidade, hoje em dia é descartável. [...] Alguns pontos, região de tórax, pessoas muito magras tem que saber como fazer, mas não precisa ser necessariamente médico... Em discussões os médicos sempre mencionam os casos de pneumotórax, mas não é que só médico não vai fazer pneumotórax no paciente...

Os efeitos colaterais decorrentes da prática de acupuntura são incomuns, geralmente tendem a estar associados à violação dos procedimentos de esterilização ou à negligencia do profissional. As poucas complicações já registradas relacionadas à acupuntura incluem a transmissão de infecções, como hepatite B; infecções nos tecidos ou ferimentos em tecidos ou órgãos, como pneumotórax ${ }^{20}$.

Segundo Dr. Evaldo, os acidentes publicados causados por acupuntura que ocorreram em dez anos, de meados da década de 1980 a 1990, foram quase 300 , e que provavelmente totaliza mais contando os que não foram publicados. Ele propôs então que se considerar que foram 600 casos no total, publicados e não publicados, "significa em média 60 casos por ano e cerca de cinco casos por mês no mundo todo". Nesta perspectiva questiona:

Quantos bilhões de inserções estão sendo realizados neste momento [...]? Quantos casos de infecção hospitalar estão acontecendo neste momento [...]? Quantos casos de erros médicos estão acontecendo agora [...]? Quer dizer, é um argumento falacioso, sórdido, mentiroso...

A acupuntura, se adequadamente aplicada, parece relativamente segura. Entretanto, se realizada inadequadamente, pode realmente causar reações adversas que por vezes podem ser tão graves que levam a óbito ${ }^{20}$.

Vale ressaltar o pertinente comentário do Dr. Francisco que se a acupuntura for regulamentada para profissionais graduados, eles têm a quem responder, os seus respectivos conselhos de classes, e com isso proteger a população de um eventual abuso.

[...] um profissional absolutamente leigo, não há nenhum sistema de controle sobre ele... Antigamente era assim, a questão era que quem quisesse comprar agulhas, montar um consultório, poderia ser médico, enfermeiro, lixeiro, pedreiro, dona de casa, manicure, engenheiro, psicólogo, o que for, poderia fazer... Então eu realmente acredito que precisaria regulamentar.

O Dr. Geraldo complementa a ideia:

Acredito que já passou da hora da acupuntura ser regulamentada para evitar diversos problemas. Toda essa discussão do Ato Médico relacionada à regulamentação da acupuntura tem também um lado positivo, pois não deixa que o curioso exerça a função porque ele vai ficando cauteloso, se não tiver um respaldo e uma formação adequada, ele não poderá exercer.

Outro argumento interessante, trazido pela Dra Célia, está relacionado à questão da formação dos profissionais não médicos. Ela traz em sua fala dois aspectos interessantes da dubitável formação de tais profissionais: o primeiro está relacionado à incapacidade dos profissionais não médicos de realizar uma anamnese completa, o segundo associa a formação de não médicos à prática de acupuntura puramente sintomatológica - "receitas de bolo". 
Para o Dr. Renato, a acupuntura é uma especialidade médica e, portanto, somente médicos podem exercê-la. Seu argumento se diferencia dos demais, visto que ele coloca a delonga da formação médica em pauta. Para ele, o longo período formativo de medicina - seis anos - oferece ao profissional experiência, aprendizado e um contato contínuo com a medicina. Em relação aos cursos de especialização para não médicos, ele se posiciona contrário, assim como a Dra Célia, pois mesmo tendo realizado um curso de graduação esses profissionais não estarão aptos para exercer a acupuntura.

\section{Situação legal}

O crescimento e o reconhecimento da acupuntura como uma prática eficaz, bem como sua inserção no SUS, através da Portaria 971, como mencionado, trouxeram uma série de discussões. A oposição entre as classes envolvidas com a prática da acupuntura - médica e as demais - vem se caracterizando por um aumento de tensões que resultou em um intenso conflito legal.

Há diversas ações jurídicas e, em 2012, retomou-se a discussão da regulamentação da acupuntura, quando o Tribunal Regional Federal da $1^{\text {a }}$ Região decidiu, no dia 27 de março de 2012, que a acupuntura poderia ser exercida somente por médicos". "Nesta ação, o Conselho Federal de Medicina questiona a legitimidade das resoluções de especialidade em acupuntura dos conselhos de Fisioterapia e Terapia Ocupacional, Enfermagem, Psicologia, Fonoaudiologia e Farmácia" ${ }^{21}$.

Esta decisão desencadeou discussões entre os demais Conselhos de Classes prejudicados.

Um processo que ficou parado desde 2004, onde essas entidades proibiam os outros Conselhos de baixar resoluções aceitando a acupuntura, de repente, sem mais nem menos, no dia 27 de março de 2012, algum juiz suplente liberou uma sentença a favor do Conselho Federal de Medicina, portanto caíram todas as liminares. (Dr. Wu)

Recentemente, temos uma discussão contrária, na segunda instância do Tribunal Federal Regional - TRF1, dizendo que os conselhos não podem regulamentar a acupuntura, pois estariam ampliando seu campo de atuação. (Dr. Delvo)

Esta controvérsia vem sendo discutida desde 2001, quando o CFM pediu à Justiça a anulação de resoluções que autorizavam enfermeiros, psicólogos, fonoaudiólogos, farmacêuticos e fisioterapeutas a praticar acupuntura. Como mencionado, o CFM defende que a acupuntura é usada para tratar dores que precisam ser diagnosticadas, atividade exclusiva dos médicos. Entretanto, os Conselhos Federais de Farmácia e Fisioterapia recorreram sobre a decisão judicial que garante aos médicos a exclusividade de exercer a acupuntura ${ }^{22}$.

Os conselhos estão recorrendo ao Tribunal Superior e ao Supremo Tribunal Federal. Se este ou aquele profissional não pode fazer, essa determinação fere o direito líquido e certo de manifestação de exercício, porque não existe regulamentação da prática da acupuntura no país. (Dr. Delvo)

Há uma série de protestos na internet contra a aprovação do Ato Médico tal como está formulado. Os receios das demais categorias estão relacionados, principalmente, ao término da multidisciplinaridade nos hospitais/serviços de saúde, pois impediria que as decisões relativas ao paciente sejam tomadas em conjunto, visto que a palavra final seria do médico, o que culminaria e caracterizaria a subordinação das demais classes à categoria médica ${ }^{23}$.

Foi possível perceber certa preocupação nas narrativas causada pela possível aprovação do Projeto de Lei 268, de 2002, comumente conhecido como Ato Médico, tanto por parte dos profissionais favoráveis quanto dos contrários à sua consolidação.

O Ato Médico é considerado, pela maioria dos colaboradores, inconstitucional e um retrocesso em relação às diretrizes e os princípios estabelecidos na Constituição de 1988 para o Sistema Único de Saúde. Numa perspectiva geral, o Ato Médico, tal como formulado a priori, compromete o modelo de atenção à saúde que vem sendo preconizado pelo SUS, baseado no atendimento universal, igualitário e integral, por equipes multiprofissionais.

Temas concernentes às necessidades de saúde há muito circulam no campo da Saúde Coletiva "em estudos sobre o acesso a serviços e cuidados, a qualidade da assistência e das práticas dos profissionais, e ainda sobre os direitos à saúde e deveres do Estado em suas políticas públicas"24. Em razão de obstáculos culturais, políticos e ideológicos de grande complexidade, observa-se a dificuldade de atingir as práticas profissionais ${ }^{25,26}$.

Desta maneira, o Ato Médico mostrou-se incompatível com os inúmeros programas que já vêm sendo desenvolvidos no Sistema Único de Saúde, impedindo a continuidade dos mesmos, que funcionam a partir do trabalho multiprofissional. Eis, portanto, a razão central apresentada pela presidente Dilma Rousseff para os vetos, que foram bem recebidos pelos profissionais de saúde, que os apontam como uma grande vitória. 
No entanto, o Conselho Federal de Medicina os chamou de "agressão aos médicos".

Ao caracterizar de maneira ampla e imprecisa o que seriam procedimentos invasivos, os dois dispositivos atribuem privativamente aos profissionais médicos um rol extenso de procedimentos, incluindo alguns que já estão consagrados no Sistema Único de Saúde a partir de uma perspectiva multiprofissional. Em particular, o projeto de lei restringe a execução de punções e drenagens e transforma a prática da acupuntura em privativa dos médicos, restringindo as possibilidades de atenção à saúde e contrariando a Politica Nacional de Práticas Integrativas e Complementares do Sistema Único de Saúde. O Poder Executivo apresentará nova proposta para caracterizar com precisão tais procedimentos ${ }^{27}$.

Nesta perspectiva, torna-se importante destacar que "a oferta de Práticas Integrativas e Complementares no Sistema Único de Saúde é estimulada para ampliar a integralidade da atenção e o acesso às mesmas, mas é um desafio incorporá-las aos serviços" ${ }^{28}$, principalmente quando o número de recursos humanos capacitados é insuficiente, assim como o financiamento voltado para a maioria das práticas ${ }^{29}$.

Com base na perspectiva integrativa, [...] a curto prazo, o modelo de atenção à saúde poderá ter custo mais elevado, em razão das mudanças na organização do sistema de saúde e nas percepções dos profissionais sobre o processo saúde-doença. Porém, a médio e longo prazos, a criação de serviços integrados levará à diminuição de gastos, devido ao cuidado integral, prevenção de doenças e promoção da saúde com que opera ${ }^{30}$.

\section{Considerações finais}

Esta pesquisa foi definida pela reflexão acerca das implicações relacionadas ao processo histórico da inserção da acupuntura nas vivências dos profissionais acupunturistas. A possibilidade e a oportunidade de ouvir diversas histórias de vida de profissionais com diferentes formações, mas com algo em comum, a acupuntura, trouxeram ricos elementos para o estudo e confirmaram nossas expectativas de que a utilização da História Oral de Vida foi a abordagem mais adequada a este estudo.

A partir das narrativas foi possível perceber que, com a aceitação cada vez mais ampla e a abertura legal desta prática por profissionais de saúde, com formação de nível superior, os representantes da classe médica altercaram esta abertura, após o reconhecimento pela categoria mé- dica em 1995, requerendo que esta prática fosse reputada como uma especialidade médica. Em decorrência desta situação, os representantes das demais categorias contestaram legalmente e por meio de solicitação coletiva o que desencadeou a ampliação desta polêmica.

Outra questão interessante nesta discussão é o exercício da acupuntura por pessoas que não apresentam formação na área da saúde ou mesmo formação universitária. É importante salientar que neste grupo estão presentes muitos dos responsáveis pela sua inserção no país. Faz-se necessário mencionar ainda que a introdução da acupuntura no Brasil, assim como em outros países, esteve intimamente relacionada ao processo de migração de profissionais do Oriente com domínio desta prática.

Por conseguinte, seria estranho cogitar uma regulamentação que não incorporasse nem mesmo os profissionais orientais formados, por exemplo, na China, o berço da acupuntura. Profissionais estes que estão dentre os mais qualificados e que introduziram esta prática no país, como mencionado. Não obstante, é fundamental tanto a regulamentação jurídica, quanto a sistematização do ensino desta prática.

Partindo do pressuposto de que a acupuntura, assim como outras práticas da MTC, apresenta sua própria racionalidade e é considerada complementar, como proposto inicialmente pela Organização Mundial da Saúde e pela Declaração de Veneza, é complicado pensar sua prática como exclusiva à classe médica.

A partir das narrativas é possível perceber os desdobramentos referentes ao Ato Médico. Como verificado anteriormente, a regulamentação da acupuntura é de extrema necessidade, principalmente, para proteger a população de profissionais inabilitados para execução desta prática. Desta forma, o que se propõe em parte das narrativas não é a exclusividade médica e nem mesmo a abertura total de sua prática, mas sim uma regulamentação que atenda às necessidades da população e dos profissionais acupunturistas que dominam o saber e o fazer.

\section{Colaboradores}

SP Rocha, F Holanda e DMC Gallian participaram de todas as etapas na elaboração do artigo e MAC Benedetto trabalhou redação final e revisão crítica. 


\section{Referências}

1. Kurebayashi LFS, Oguisso T, Freitas GF. Acupuntura na enfermagem brasileira: dimensão ético-legal. Acta paul. enferm. 2009; 22(2):210-212.

2. Brasil. Ministério da Saúde (MS). Política Nacional de Práticas Integrativas e Complementares. [documento da internet]. Ministério da Saúde, Municipais de Saúde Brasília: Ministério da Saúde, 2006. [acessado 2009 ago 10]. Disponível em: <http://dtr2004.saude.gov.br/dab/ docs/publicacoes/geral/pnpic.pdf $>$.

3. Wen TS. Acupuntura Clássica Chinesa. 10ª ed. São Paulo: Cultrix; 1995.

4. Souza EFAA, Luz MT. Análise crítica das diretrizes de pesquisa em medicina chinesa. Hist. cienc. saude-Manguinhos 2011; 18(1):155-174.

5. Maciocia G. Os Fundamentos da Medicina Chinesa. São Paulo: Editora Roca; 1996.

6. Pai HJ. Acupuntura: de terapia alternativa a especialidade médica. São Paulo: CEIMEC; 2005.

7. Luz MT. Cultura contemporânea e medicinas alternativas: novos paradigmas em saúde no fim do século XX. Physis 1997; 7(1):13-43.

8. United Nations Educational, Scientific and Cultural Organization (UNESCO). Declaração de Veneza, 1986. Comunicado final do colóquio: A ciência diante das fronteiras do conhecimento. Veneza - Itália, 1986. [documento da internet]. [acessado 2012 jun 8]. Disponível em: http://unesdoc.unesco.org/images /0006/000685/068502por.pdf.

9. Jacques LM. As Bases Científicas da Medicina Tradicional Chinesa. São Paulo: Annablume; 2005.

10. Gallian DMC. 75x75: EPM/Unifesp, uma história, 75 vidas. São Paulo: Unifesp, 2008.

11. Meihy JCSB. Manual de história oral. $5^{\mathrm{a}}$ ed. São Paulo: Loyola; 2005.

12. Meihy JCSB, Holanda, F. História Oral. Como fazer, como pensar. São Paulo: Contexto; 2007.

13. Borkan J. Immersion/Cristalization in: Miller WC, Crabtree BF, editors. Doing Qualitative Research. USA: Sage Publications; 1999.

14. Nascimento MC. De panacéia mística a especialidade médica: a acupuntura na visão da imprensa escrita. Hist. cienc. saude-Manguinhos 1998; 5(1):99-113.

15. Conselho Federal de Medicina. Publicado acórdão do TRF que restringe exercício da acupuntura somente a médicos. Conselho Federal de Medicina. 2012. [documento da internet]. [acessado 2013 jan 13]. Disponível em: http://portal.cfm.org.br/index.php?option=com_ content\&view=article\&id=22788:publicado-acordaodo-trf-que-restringe-exercicio-da-acupuntura-somente -a-medicos\&catid $=3$.

16. Brasil. Senado Federal. Pontos polêmicos do projeto do ato médico. [documento da internet]. Senado Federal. Brasília - Senado Federal. 2012. [acessado 2012 dez 23]. Disponível em: http://www.senado.gov.br/noticias/agencia /quadros/qd_369.html.
17. Ernst E, White A. Acupuntura uma Avaliação Científica. São Paulo: Manole, 2001.

18. Jonas WB, Levin JS. Essentials of Complementary and Alternative Medicine. Baltimore: Lippincott, Williams \& Wilkins; 1999.

19. Bauer MD. O poder da cura da acupressura e da acupuntura. São Paulo: Pensamento; 2007.

20. Jonas WB, Levin JS. Tratado de Medicina Complementar e Alternativa. São Paulo: Editora Manole; 2001.

21. Araújo JE. About the rights of practicing acupuncture in Brazil. Rev. bras. fisioter. 2012; 16(4):V-VI.

22. Brasil. Portal Brasil. Conselhos vão recorrer de decisão que garante apenas a médicos exercer acupuntura. 2012. [documento da internet]. [acessado $2012 \mathrm{dez} 20$ ]. Disponível em: http://www.brasil.gov.br/noticias/arquivos /2012/03/30/conselhos-vao-recorrer-de-decisao-quegarante-apenas-a-medicos-exercer-acupuntura.

23. Brasil. Portal de Notícias. Projeto do Ato Médico põe profissões da saúde em guerra. 2012. [documento da internet]. [acessado $2012 \mathrm{dez}$ 17]. Disponível em: http://www12.senado.gov.br/noticias/jornal/edicoes /2012/04/24/projeto-do-ato-medico-deflagra-disputa -em-profissoes-da-saude.

24. Schraiber LB. Necessidades de saúde, políticas públicas e gênero: a perspectiva das práticas profissionais. Cien Saude Colet 2012; 17(10):2635-2644.

25. Campos GSW. A mediação entre conhecimento e práticas sociais: a racionalidade da tecnologia leve, da práxis e da arte. Cien Saude Colet 2011; 16(7):3033-3040.

26. Schraiber LB. Quando o "êxito técnico" se recobre de "sucesso prático": o sujeito e os valores no agir profissional em saúde. Cien Saude Colet 2011; 16(7):30413042.

27. Brasil. Planalto. Casa Civil. Mensagem no 287, de 20 de julho de 2013. Dispõe sobre o exercício da Medicina. Mensagem de veto. Diário Oficial da União 2013; 11 jul.

28. Santos MC, Tesser CD. Um método para a implantação e promoção de acesso às Práticas Integrativas e Complementares na Atenção Primária à Saúde. Cien Saude Colet 2012; 17(11):3011-3024.

29. Sousa IMC, Vieira ALS. Serviços Públicos de saúde e medicina alternativa. Cien Saude Colet 2005; 10(Supl.):255-266.

30. Tesser CD, Luz MT. Racionalidades Médicas e integralidade. Cien Saude Colet 2008; 13(1):195-206.

Artigo apresentado em 05/10/2013

Aprovado em 06/01/2014

Versão final apresentada em 10/01/2014 